\title{
Assessment of noise levels in the intensive care unit using Apple Watch
}

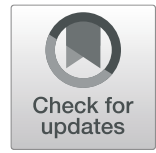

Tommaso Scquizzato ${ }^{1,2^{*}}$, Arianna Gazzato', Giovanni Landoni ${ }^{1,2}$ and Alberto Zangrillo ${ }^{1,2}$

Alarms from monitors, medical devices and staff activities increase noise levels in the Intensive Care Unit (ICU) and may disrupt sleep patterns [1] contributing to the development of delirium and post-intensive care syndrome [2]. The World Health Organization (WHO) recommend that hospital noise levels should not exceed 35 A-weighted decibels (dBA) during the day and $30 \mathrm{dBA}$ at night [3]. However, daytime noise levels in ICU were found of around $60 \mathrm{dBA}$ [4]. Apple Watch (Series 4 and 5) takes advantage of the internal microphone to regularly sample sound levels in the environment and might play a role in monitoring noise in the ICU.

We investigated the feasibility of analyzing data from an Apple Watch to measure noise levels in the ICU. Accordingly, we exported Health data from the personal Apple Watch of a nurse working in a 14 beds referral cardiothoracic ICU managing patients after cardiac surgery and those with cardiogenic shock, refractory cardiac arrest, and respiratory failure. Noise levels were compared between daytime (7 a.m. - 11 p.m.) and night-time (11 p.m. - 7 a.m.). Data extraction and statistical analysis were performed with the "Pandas" Python Library. An open-source Jupyter notebook has been made available together with this publication on GitHub (https://github.com/tscquizzato/ICU-Noise-Levels-Apple-Watch) with a step-bystep guide to repeat our experience.
Consecutive 1086 samples measured during 48 shifts (48\% from 7 a.m. to $7: 30$ p.m. and $52 \%$ from 7 : 15 p.m. to 7:15 a.m.) between November 1, 2019 and February 29, 2020 were extracted. The average sound level was $66 \pm 6.1 \mathrm{dBA}$ (Fig. 1). Sound levels significantly differed between daytime and night-time (67 \pm $6.7 \mathrm{dBA}$ vs. $64 \pm 4.2 \mathrm{dBA}, p<0.001$ ) (Fig. 2). The highest sound level was $89 \mathrm{dBA}$ and was recorded on Monday between $12 \mathrm{a} . \mathrm{m}$. and $1 \mathrm{p} . \mathrm{m}$. The lowest one was $31 \mathrm{dBA}$ between 3 p.m. and 4 p.m. on Sunday. In only $2.8 \%$ of samples, noise levels during daytime were below $35 \mathrm{dBA}$. During the night, sound levels were always above $30 \mathrm{dBA}$.

The analysis of noise levels in the ICU using an Apple Watch is feasible and easy to perform. Overall, noise levels were almost always above the recommended values, consistent with previously published studies [4]. The role of wearable devices to measure noise levels deserves to be further investigated. Such devices might also be worn by patients to accurately quantify noise levels and compare with sleep quality and recovery.

* Correspondence: scquizzato.tommaso@hsr.it

'Department of Anesthesia and Intensive Care, IRCCS San Raffaele Scientific Institute, Milan, Italy

${ }^{2}$ Faculty of Medicine, Vita-Salute San Raffaele University, Milan, Italy licence and your intended use is not permitted by statutory regulation or exceeds the permitted use, you will need to obtain permission directly from the copyright holder. To view a copy of this licence, visit http://creativecommons.org/licenses/by/4.0/ The Creative Commons Public Domain Dedication waiver (http://creativecommons.org/publicdomain/zero/1.0/) applies to the data made available in this article, unless otherwise stated in a credit line to the data. 


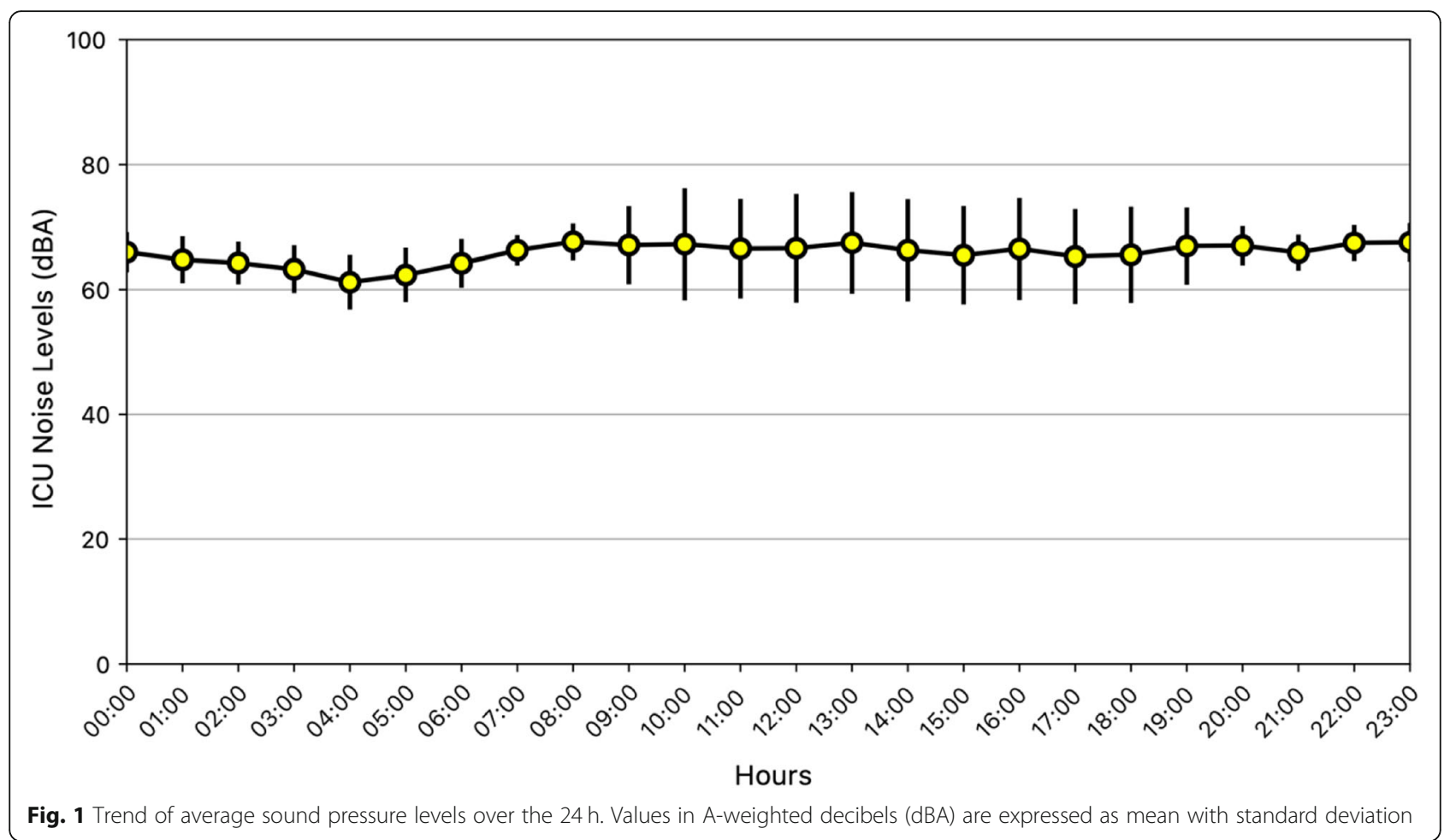

Fig. 1 Trend of average sound pressure levels over the $24 \mathrm{~h}$. Values in A-weighted decibels (dBA) are expressed as mean with standard deviation

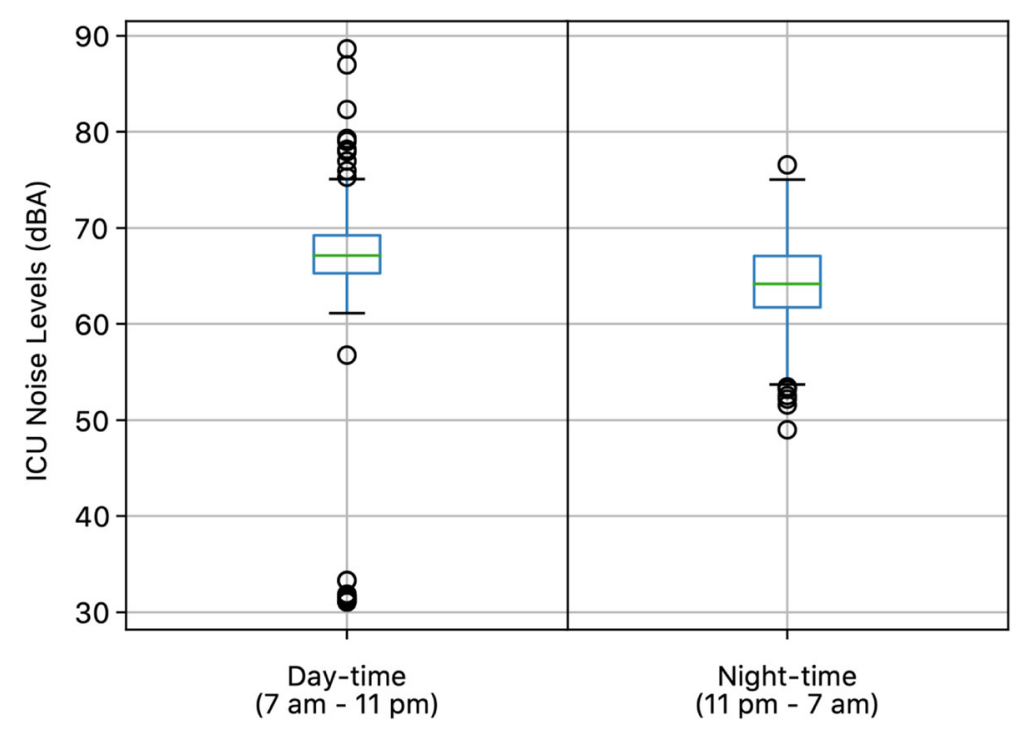

Fig. 2 Boxplot comparing sound pressure levels during daytime (7am - $11 \mathrm{pm})$ and night-time (11 pm - $7 \mathrm{am})$ 
Abbreviations

ICU: Intensive care unit; dBA: A-weighted decibels; WHO: World Health Organization

\section{Acknowledgements}

None.

Authors' contributions

All authors participated in study concept and design, drafting the manuscript and approved the final version.

\section{Funding}

None.

Availability of data and materials

Not applicable.

Ethics approval and consent to participate

Not applicable.

\section{Consent for publication}

Not applicable.

\section{Competing interests}

The authors declare that they have no competing interests.

Received: 18 March 2020 Accepted: 25 March 2020

Published online: 06 April 2020

\section{References}

1. Freedman NS, Gazendam J, Levan L, Pack Al, Schwab RJ. Abnormal sleep/ wake cycles and the effect of environmental noise on sleep disruption in the intensive care unit. Am J Respir Crit Care Med. 2001;163:451-7.

2. Weinhouse GL, Schwab RJ, Watson PL, Patil N, Vaccaro B, Pandharipande P, Ely EW. Bench-to-bedside review: delirium in ICU patients - importance of sleep deprivation. Crit Care. 2009;13(6):234.

3. Berglund B, Lindvall T, Schwela DH \& World Health Organization Occupational and Environmental Health Team. Guidelines for community noise 1999. http://www.who.int/iris/handle/10665/66217.

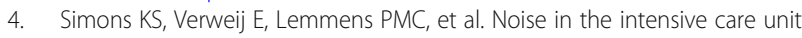
and its influence on sleep quality: a multicenter observational study in Dutch intensive care units. Crit Care. 2018;22:250 https://doi.org/10.1186/ s13054-018-2182-y.

\section{Publisher's Note}

Springer Nature remains neutral with regard to jurisdictional claims in published maps and institutional affiliations. 